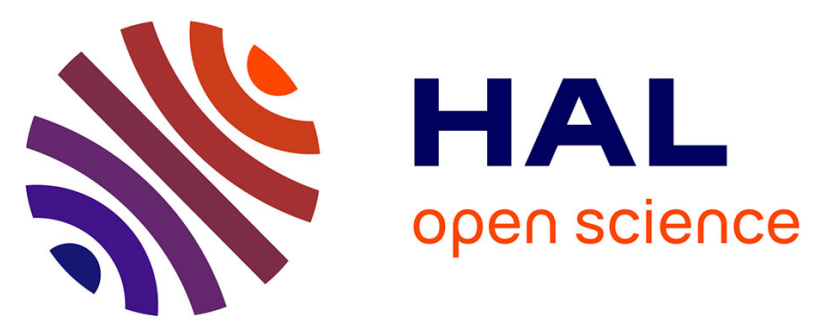

\title{
Territorial analysis of energy consumption of a small remote island: Proposal for classification and highlighting consumption profiles
}

\author{
Fiona Sora, Jean-Philippe Praene
}

\section{- To cite this version:}

Fiona Sora, Jean-Philippe Praene. Territorial analysis of energy consumption of a small remote island: Proposal for classification and highlighting consumption profiles. Renewable and Sustainable Energy Reviews, 2016, 59, pp.636-648. 10.1016/j.rser.2016.01.008 . hal-01273889

\section{HAL Id: hal-01273889 \\ https://hal.univ-reunion.fr/hal-01273889}

Submitted on 7 Apr 2016

HAL is a multi-disciplinary open access archive for the deposit and dissemination of scientific research documents, whether they are published or not. The documents may come from teaching and research institutions in France or abroad, or from public or private research centers.
L'archive ouverte pluridisciplinaire HAL, est destinée au dépôt et à la diffusion de documents scientifiques de niveau recherche, publiés ou non, émanant des établissements d'enseignement et de recherche français ou étrangers, des laboratoires publics ou privés. 


\title{
Territorial analysis of energy consumption of a small remote island: Proposal for classification and highlighting consumption profiles
}

\author{
Fiona Bénard-Sora, Jean Philippe Praene
}

Université de La Réunion, Reunion

\begin{abstract}
A B S T R A C T
The purpose of this work is to understand the structure of electricity consumption at the level of municipalities in an island area. Due to the depletion of fossil energy resources, some territories are more affected than others, especially because of their location and dependence. Such is the case of islands, such as Reunion Island. For these territories, it is important to understand the localized needs to prepare for energy supply. This work raises the issue of energy consumption in Reunion: what are its determinants? Two methods are used to illustrate the problem, and the matter of the disparity in the territory is highlighted with at least three types of energy consumption profiles at the municipal level that reflect the issues of localized energy management.
\end{abstract}

\section{Contents}

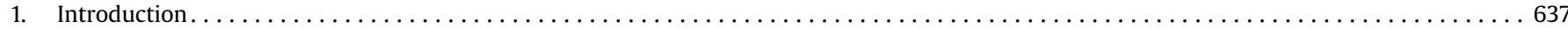

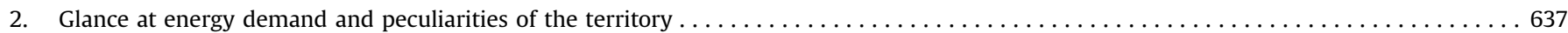

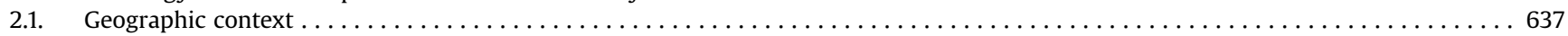

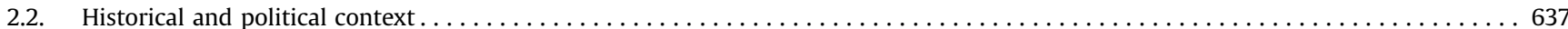

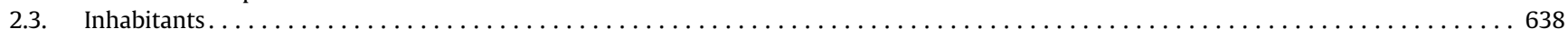

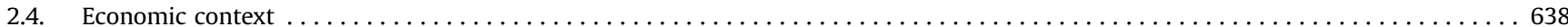

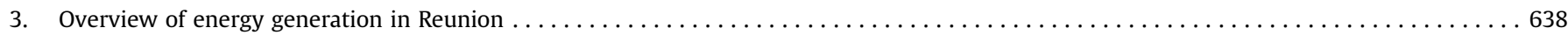

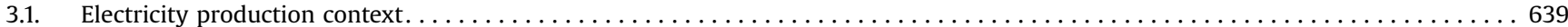

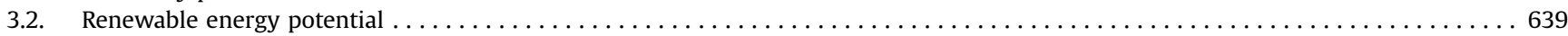

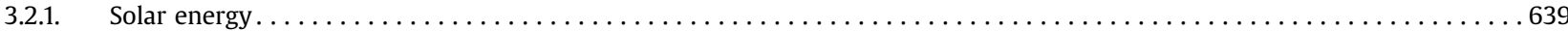

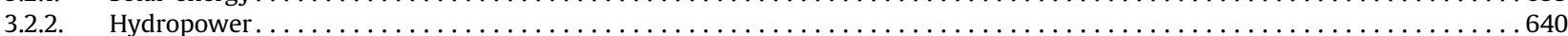

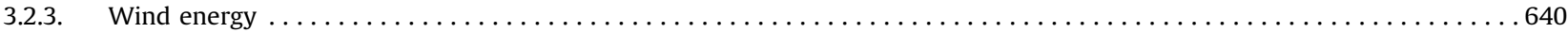

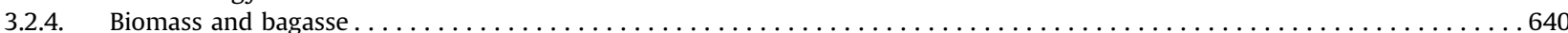

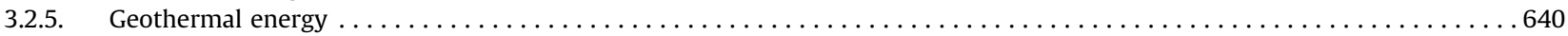

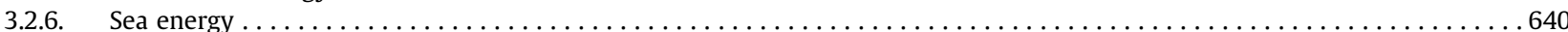

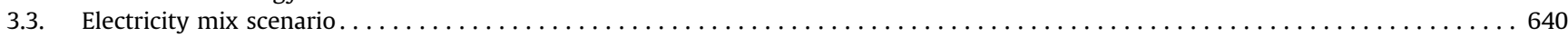

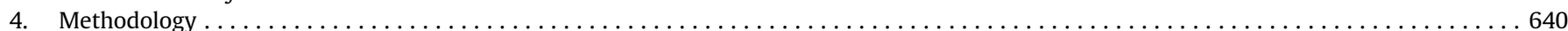

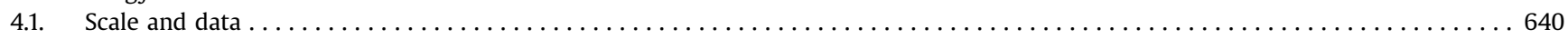

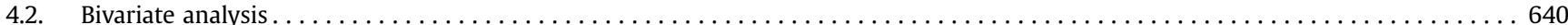

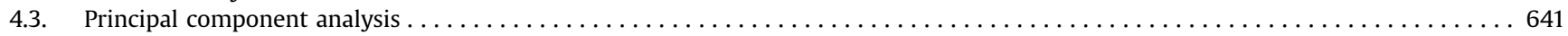

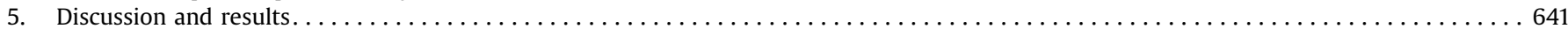

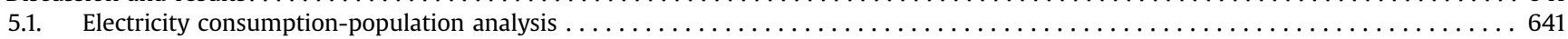

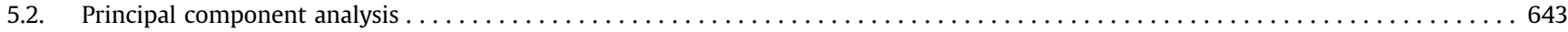

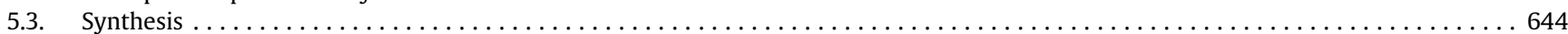

E-mail a ddresses: fiona.sora@univ-reunion.fr (F. Bénard-Sora), jean-philippe.praene@univ-reunion.fr (J.P. Praene). 


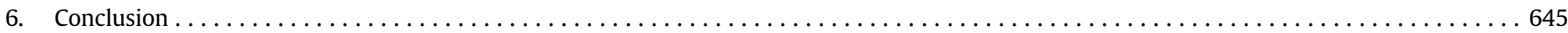

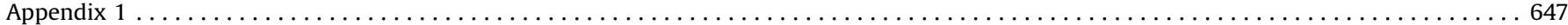

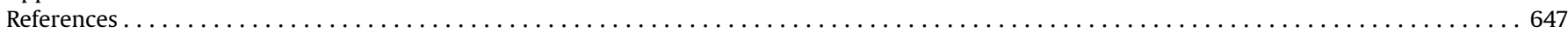

\section{Introduction}

Small non-interconnected islands present a particular context as an isolated territory with limited resources, and the challenge of energy autonomy takes a larger dimension than a mainland territory, accentuated by the depletion of fossil fuel resources. The main objective of these territories is to become a near zero energy island [19]. Several studies have approached these questions from the perspective of the potential and policies for renewable energy sources (RES) $[12,16,18,23,3,7]$. It is obvious that without any policy incentives, the deployment of renewable energy on islands could be compromised [19,22]. The establishment of Smart Grid systems, such as Demand Response, are part of incentive measures to support the development of renewable energy, in particular by encouraging customers to consume off-peak energy. For example, simulations on Reunion Island have shown that the use of Demand Response solutions could help reduce the total installed capacity (renewable energy) by $16.7 \%$ [2].

However, one of the issues with renewable energy is their intermittent nature, which causes storage problems and issues related to matching electricity supply and demand. Current storage technologies are not suitable for the integration of renewable energy in large-scale systems [3].

A solution that could be advanced is to consider a finer scale, with the introduction of micro-systems to respond to a localized demand. This solution has already been identified as best suited for an island, for example Malta [13]. In island areas with rich potential for renewable energy, this solution could accelerate progress towards energy independence. The objective of this article is primarily descriptive: the integration of micro-systems involves identifying energy needs. Thus, to describe the request to a fine level of division of the territory, one must be able to understand the factors that explain demand. The first factors that suggest themselves are related to population, housing and activities.

Consider the particular case study of Reunion Island. This is a French overseas department and an ultra-peripheral region of the European Union (EU) located in the Indian Ocean. Its estimated population was 841,000 in 2013 [10]. The demographic transition of Reunion is one the fastest observed in the world, comparable to Singapore or Hong-Kong [24,9]. According to its demographic variation, Reunion will achieve its transition in approximately 2040.

This demographic transition has a significant influence on the energy consumption and pushes the population to be considered as a main factor behind the consumption of electricity. However, other factors, such as economic activity, land pressure and geographic constraints, could be important parameters for understanding energy consumption. In order to prepare for supply, it therefore seems essential to identify the main determinants of energy consumption. The demographic situation of the island is so special that the track of the population as a determinant of consumption can be advanced. Energy demand is indeed one of the main components for energy policy-making, identified most notably for Pacific Island [25]. In this article, we therefore look at Reunion and we will check two assumptions. Firstly, we considered that the population is a sufficient factor to explain electricity consumption.

Secondly, we have introduced other explicative factors through a multi-dimensional Principal Component Analysis. The comparison of these two approaches allows us to make conclusions about sub-regional electricity consumption patterns. The two methods allow us to highlight not only the importance of the population factor in determining energy consumption but also existing regional disparities.

Then, one of the questions that arises is the scale of the analysis. Which scale is advisable with which to work? In the case of a small island area such as Reunion, there are few study subdivisions. We opted in this work to use the city level, which allows us to have a sample size of 24 (all 24 cities of the island). The data are related to population and energy consumption.

\section{Glance at energy demand and peculiarities of the territory}

Reunion Island is the most outer region of the European Union. It has a total area of $2512 \mathrm{~km}^{2}$. The territory is a densely but disparately populated island with 334 people $/ \mathrm{km}^{2}$ in 2012 .

The choice of Reunion Island as the object of investigation is not insignificant. With an unfinished demographic transition, the population of the island doubled in just 40 years (INSEE data). Meanwhile, the energy situation has experienced a particular development: the demographic growth has inevitably led to profound changes in the local energy landscape, and we witnessed the transition from energy independence in the early 1980s to a heavy dependence today on imported fossil resources. We can indeed highlight a high linear correlation (0.99) between population size and annual electricity consumption over the period 2000-2012 $2^{1}$ (see Fig. 1).

The study of customer segmentation and their share of electricity consumption on the island shows the strong impact of the population with the largest portion of consumption (44.8\% of total consumption) just before the "heavy users" (e.g., hospitals, 35.4\% of the total consumption) [17].

\subsection{Geographic context}

The geography of the island presents a constrained and restricted terrain. In addition to its insularity, the island has two volcanic massives at its center: the Piton des Neiges and the Piton de la Fournaise, whose collapse due to erosion has formed three calderas. The island is thereby marked by a succession of slopes and gullies that make the terrain difficult to exploit outside the coasts. Therefore, the coastal zone (from 0 to $400 \mathrm{~m}$ in altitude) contains $80 \%$ of the inhabitants. Furthermore, the island is also considered a protected area under the category of Natural Park (the centre of the island), which also explains the concentration of the population on the coast.

\subsection{Historical and political context}

As an old French colony, the occupation of the island space is dichotomous, consistent with colonization that favors the most flexible and advantageous coast [4]. Reunion Island has been a French territory since 1946 . This event sets in motion a social and economic process as the island catches up with France. Before

\footnotetext{
${ }^{1}$ Access to this type of data does not allow us to evaluate a broader period.
} 
1946, the road network was rare (only $44 \mathrm{~km}$ of tarred roads), only one house in a thousand had electricity, the harbor was in poor condition, etc. As a French territory, the island began not only the process of increasing economic growth and social progress but also population growth. This process moved particularly fast, and in a few years, the progress was observable: for example, the tarred roads increased from 40 to $400 \mathrm{~km}$, and in $201069.9 \%$ of the households owned a car (INSEE, RP2010). Notably, this process is accompanied by an increase in the equipment rate of metropolitan households and the development of residential air conditioning, which influence the growth of power consumption [14]. Although agriculture has historically been the main resource of the island, with departmentalization agriculture declined in favor of the service sector, and this industry is limited because of the size of the territory. However, agriculture is now maintained by political efforts for cultural heritage reasons [21].

\subsection{Inhabitants}

With 828,581 inhabitants in 2011, the population has increased 4.2 times since 1930 and by 3.7 times since departmentalization (INSEE data). Demographic forecasts predict a million inhabitants by 2030 . With such a demographic context associated with a constrained relief, Reunion Island presents special challenges in term of urbanization. Indeed, the population and activities are

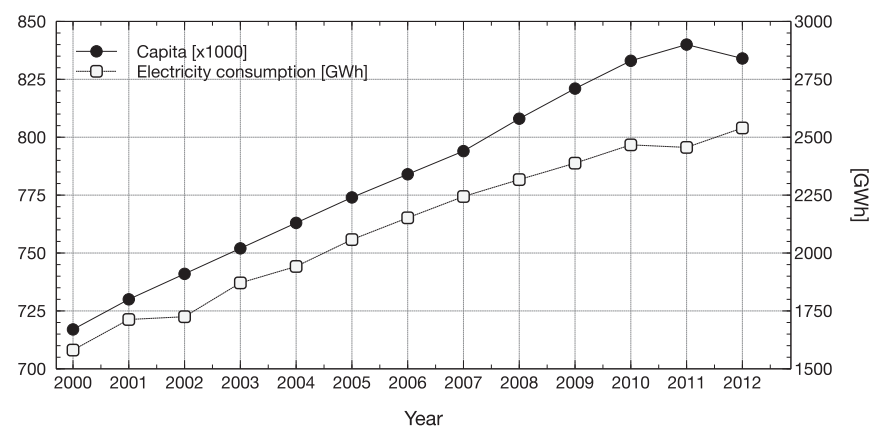

Fig. 1. Evolution of population and electricity consumption over the period 20002012. concentrated on the coast (see Fig. 2). In 1998, Jauze highlighted the dominance of a northwest coastal belt (from Saint-Denis to Saint-Pierre) which he explained using the dependence of the island on the physical geography and the location of the main interchange with the outside [11].

\subsection{Economic context}

With a Gross Domestic Product (GDP) of 16.1 billion euros in 2012, Reunion Island shows a GDP per capita of 19,090 euros, which corresponds to $61.5 \%$ of the national level. GDP increased by 2.8 times compared to its level in 1993, which shows the growth experienced by the island in the 1990s. Despite an economic slowdown affecting Reunion since 2009, its annual GDP growth rate has been approximately $5.6 \%$ in the last decade, while the population grew nearly $16 \%$ in the same period. This growth rate fills the gap on the national level in terms of per capita wealth.

The economy of the island is particularly dependent on merchant services and health, education and social action services, which account for approximately $55 \%$ of the added value. Agriculture represents only $1 \%$ of the total value added, while the construction sector accounts for only 7.3\% (INSEE, regional economic accounts).

\section{Overview of energy generation in Reunion}

Reunion is characterized by a humid tropical climate under the influence of easterly winds. Two climatic seasons are distinguished:

- the austral winter (from May to October), with mild temperatures, low rainfall and winds;

- the austral summer (from November to April), with higher temperatures, very high moisture and substantially greater rainfall.

Because of its insularity, Reunion is strongly dependent on energy from expensive imports of oil derivatives. The island is too far from the African continent ( $>1000 \mathrm{~km}$ ) to link to any energy networks. To face its rapid economic development, a fossil energy

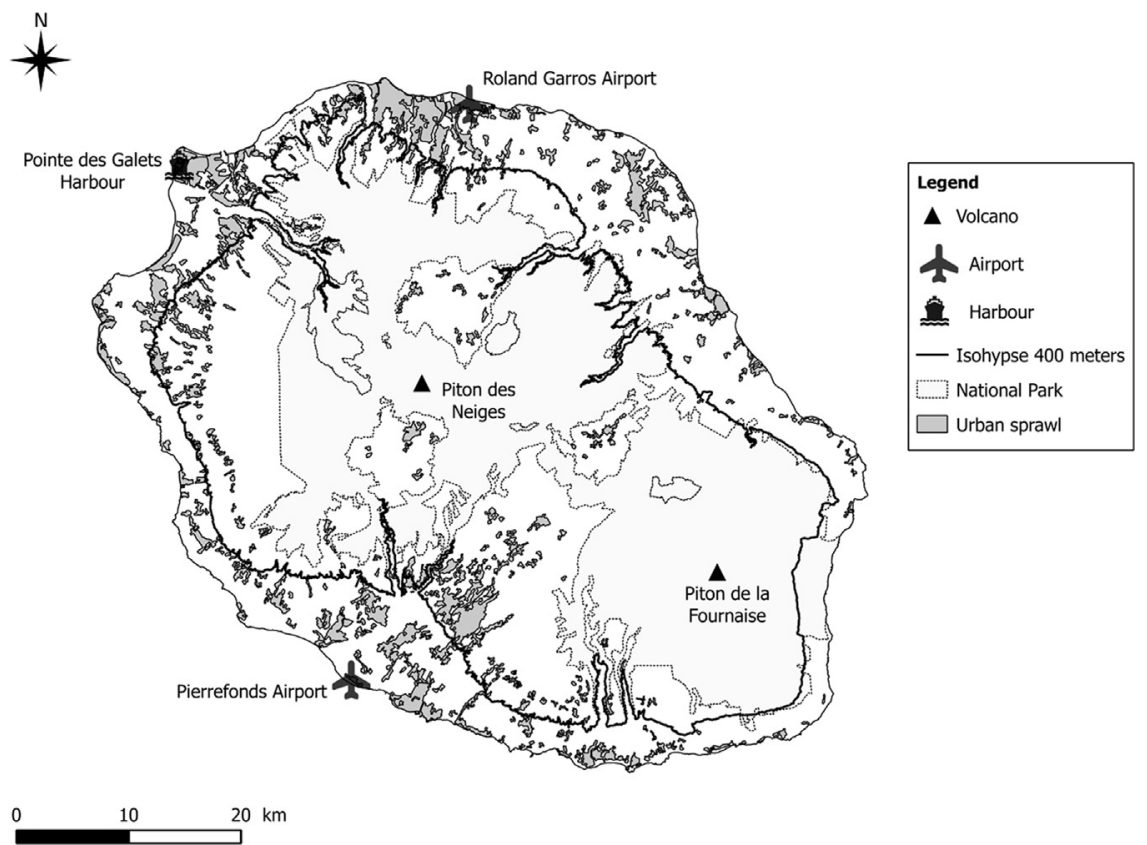

Fig. 2. Reunion Island, a particular context. Data source: IGN BD TOPO ${ }^{\circledR}$. DEAL. 
supply was developed at the end of 1980s, whereas previously the electricity production of the island was mainly hydroelectric [6].

Currently, the imports of petroleum products go mainly to the transport sector (50\%/608 ktoe) and electricity production (45\%/ 554 ktoe). Multi-year trends highlight a $34.4 \%$ growth (equivalent to 886.8 ktoe) between 2000 and 2012, averaging 2.5\% per year [17].

\subsection{Electricity production context}

In 2012, electricity consumption was $2539.9 \mathrm{GW}$ h (in 2003, it was $1871 \mathrm{GW} \mathrm{h}$ ) representing an increase of $2.2 \%$ over the previous year [17]. Household electricity demand represents more than $41 \%$ of the total consumption. Nevertheless, it should be noted that the energy intensity has decreased by 6.1\% from 3.6 MWh in 2006 to 3.38 MWh (EDF ${ }^{2}$ subscriber). This decrease is the result of an incentive policy to promote an energy management program. The annual growth rate of electricity was $5.3 \%$ in the $2000-2005$ period, $3.5 \%$ in the $2006-2010$ period, and this rate has stagnated to $2.0 \%$ since 2010 . This is undoubtedly due, first and foremost, to the slowdown of the economy of Reunion Island that has been marked by the end of a major construction project: the Route des Tamarins road.

The production of electricity and energy demand are covered almost entirely by fossil resources. As shown in Fig. 3, 65.4\% of electricity production is from primary fossil energy (petroleum and coal). For this reason, with a ratio of $200 € / \mathrm{MW} \mathrm{h}$, the cost of electricity production is fairly high compared with the mean value in France, where the electricity price is currently $110.60 € / \mathrm{MW} \mathrm{h}$.

Though oil derivatives are important in the electricity mix, it would be wrong to not consider renewable energy sources (RES). In 1985, hydropower plants accounted for over $90 \%$ of electricity consumption [6].

\subsection{Renewable energy potential}

The energy autonomy of a small remote island such as Reunion can be achieved only through the deployment of renewable energy solutions. The challenge is to both reconcile the rise of renewable energy and guarantee the security of electrical power.

In 1999, the Regional Council initiated the first energy programme for the development of renewable energy, called PRERURE. ${ }^{3}$ A Steering Committee was established at the end of 2013, in line with the commitments made in the SRCAE. ${ }^{4}$ The targets of the energy strategy are: $50 \%$ of the energy production of the island must come from renewable energy by 2020 and $100 \%$ by 2030 .

Due to its sub-tropical climate, Reunion has a huge potential from several RES (solar, wind, sea energy, and biomass). The island's ambition is to be among the first small self-sufficient islands in the world by using RES (both in electricity and transport).

Thus it is necessary to focus on:

- Energy efficiency: the recent development of photovoltaic energy was just enough to stabilize the share of the production of electricity from RES. The island's self-sufficiency capacity is currently $87.2 \%$. As shown in Fig. 4, electricity from RES is still very moderate and decreasing because electricity consumption has increased from 1871 to $2540 \mathrm{GW}$ h.

\footnotetext{
${ }^{2}$ EDF : French electricity provider

${ }^{3}$ Regional plan for renewable energies and rational use of energy.

${ }^{4}$ Climate, air quality and energy regional plan.
}
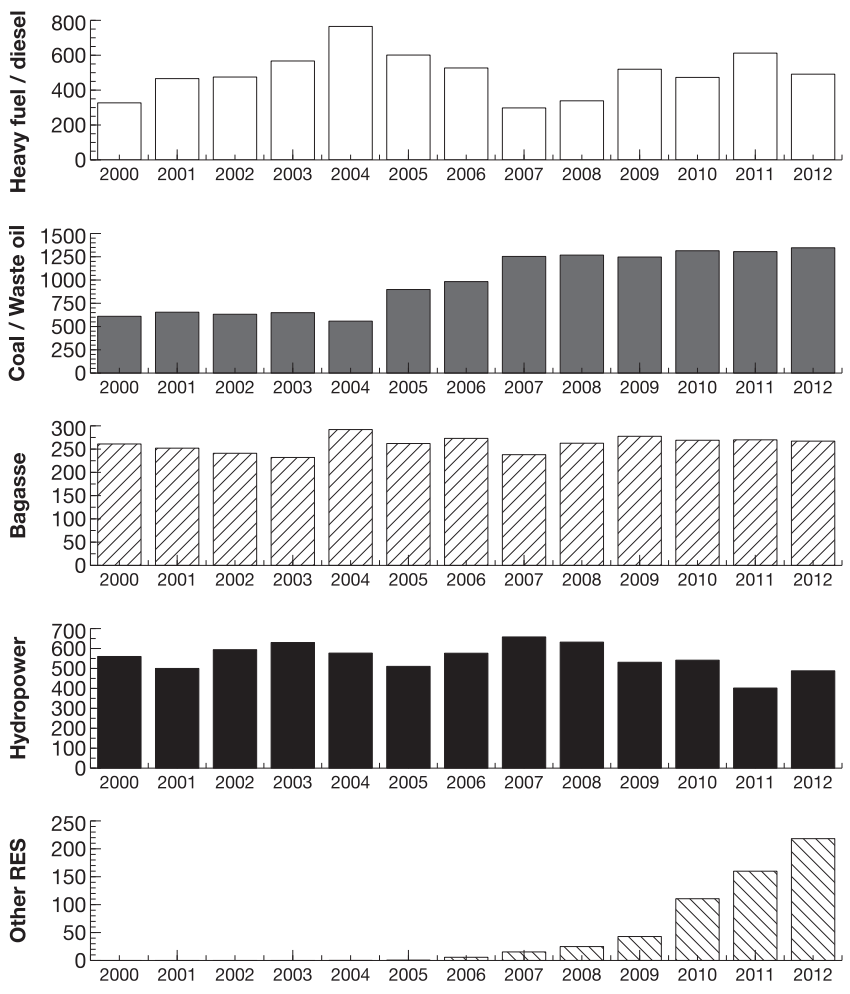

Fig. 3. Electricity mix [GW h] of Reunion since 2000.

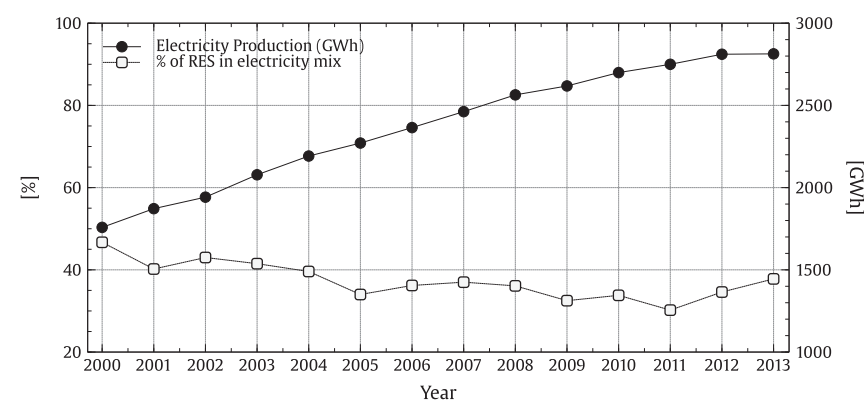

Fig. 4. Reunion self-sufficiency rate in electricity from 2000 to 2012.

- RE guarantee: secure non-intermittent production, which will be available throughout the year. Thus, production will be stabilized and consequently non-disruptive for the electrical network.

\subsubsection{Solar energy}

The daily solar radiation in Reunion is approximately $6.1 \mathrm{~kW} \mathrm{~h} /$ $\mathrm{m}^{2}$, for a range of $1400-2900 \mathrm{~h}$ per year. Two principal developments have been investigated in last two decades. The first concerns solar water heaters. Since 2009, the RTAA DOM ${ }^{5}$ requires the use of solar energy for the water heating system in all new construction. With a density of $637 \mathrm{~m}^{2} / 1000$ residents in 2012, Reunion is ranked 2nd in Europe after Cyprus $\left(837 \mathrm{~m}^{2} / 1000\right.$ resident) in terms of thermal solar collectors installed. At the end of $2012,533,560 \mathrm{~m}^{2}$ (including $34,550 \mathrm{~m}^{2}$ of collective systems) of SWH (Solar Water Heating) are operational. The total electricity consumption avoided is $207.8 \mathrm{GW}$ h.

The potential of additional saving for 2030 is estimated at:

- 30-50 GW h for collective housing;

- 120-160 GW h for individual housing.

\footnotetext{
${ }^{5}$ RTAA DOM: Specific thermal, acoustic and ventilation standards for French over-seas departments
} 
In 2013, Reunion ranked fifth in Europe (2nd in France after Corse) in installed photovoltaics with $181.5 \mathrm{Wp}^{6} /$ resident. Between 2011 and 2012, PV capacity increased by 34.3\%. The development of photovoltaic systems declined in the last year because of low eligibility for tax exemptions. In 2010, a first decree decreased financial aid by $12 \%$ for installations producing more than $3 \mathrm{kWp}$ [15]. A second decrease of $20 \%$ was implemented in 2012 to fix a feed-in tariff at $0.46 € / \mathrm{kW} h$ [8]. In Reunion, the development of the photovoltaic industry is facing the limit of $30 \%$ intermittent energy that can be injected onto the EDF network. This limit was put in place to ensure the stability of the local power grid. This limit has almost been reached by the island and could put a stop to the photovoltaic industry. The development of energy storage systems currently appears to be a second wind for the PV industry.

Thus, in 2025, the expected installed power is $310 \mathrm{MW}$ [5]. This scenario has been provided by EDF scenarios.

\subsubsection{Hydropower}

With six plants, hydropower represents $14.6 \%$ (133 MW) of electricity production. The percentage is relatively low the last three years because of average rainfall that ran significantly below normal. The potential is currently estimated at $45 \mathrm{MW}$ more by 2020 and an additional $5 \mathrm{MW}$ of micro/pico-hydropower plants for a total of $183 \mathrm{MW}$.

\subsubsection{Wind energy}

In view of the cyclonic context of Reunion, it is necessary to install folding wind turbines in strong winds. Thus, the additional cost generated in investment and operation during cyclonic winds limit the investment in wind energy on the island despite significant potential on the east coast. Two onshore wind farms exist on the east side of the island, for a total production of $18.2 \mathrm{GWh}$, which is equivalent to a 55.6\% increase compared to 2011 .

\subsubsection{Biomass and bagasse}

In 2012, the installed power for coal - bagasse is $210 \mathrm{MW}$. The annual production is $267.1 \mathrm{GW} \mathrm{h}$. A biogas unit has produced 9.6 GW h ( $+50 \%$ compared to 2011). The biogas plant of "Distillerie Rivière du Mât" avoided the consumption of $670 \mathrm{~m}^{3}$ of domestic heating fuel that is equivalent to $0.6 \mathrm{ktoe}$. The potential in biomass development is estimated to range from 11 to $17 \mathrm{MW}$ in 2020.

\subsubsection{Geothermal energy}

Geothermal energy is a very attractive resource for Reunion. This potential is characterized by the high geothermal gradients of approximately $18-20^{\circ} \mathrm{C} / 100 \mathrm{~m}$. It is not currently possible to define a target due to the lack of reliable knowledge of the resource. However, an expected capacity of $30 \mathrm{MW}$ is anticipated for 2030.

\subsubsection{Sea energy}

The opportunity of sea energy has been investigated in research projects [20]. Ocean thermal energy conversion (OTEC) is currently under study using a $10 \mathrm{MW}$ pilot to the south of the island. OTEC is expected to have an installed capacity of $130 \mathrm{MW}$ by 2030.

Wave energy exploitation based on CETO technology is also being investigated. The potential capacity has been is evaluated at $30 \mathrm{MW}$ in 2020 and $40 \mathrm{MW}$ in 2030.

The third type of project is a sea water air-conditioning system that has been chosen by a hospital to save $50 \%$ of its electricity

\footnotetext{
${ }^{6}$ Watt-peak
}

since $60 \%$ of the electricity consumption of the hospital is due to air-conditioning.

\subsection{Electricity mix scenario}

In 2013, the renewable energy penetration in the electricity mix was $37.8 \%$. The current projection of the evolution of this mix is $49 \%$ from RES in 2020 and $61 \%$ in 2030 . This projection does not include the evolution of electricity consumption due to incentives from energy policy. The emergence of the concept of resilience of a territory is discussed more and more, but not as an impact resistance indicator to global change. However, it appears to be a useful tool to evaluate the adaptability, reactivity and flexibility of territory to move from one steady state to another. This evolution must include the future energy transition model of Reunion Island to integrate multi-disciplinary information.

\section{Methodology}

\subsection{Scale and data}

For reasons of data availability, we chose to work at the municipal level. The aim is to highlight the determinants of municipal energy consumption to propose a classification of the towns on the island. We are working on the whole territory of the island, which comprises 24 municipalities of various sizes: an average of $104.3 \mathrm{~km}^{2}$ and a standard deviation of $64 \mathrm{~km}^{2}$. Le Port is the smallest municipality with $16 \mathrm{~km}^{2}$, and the largest is Saint-Paul with $240.7 \mathrm{~km}^{2}$.

Population data are from Census data from INSEE and energy consumption data are from studies by the regional energy agency, ARER. Our work focuses on the year 2010, which is the date of the last census, when Reunion has 821,136 inhabitants. The most populated municipality is the capital, Saint-Denis, with 145,022 inhabitants and the least populated municipality is Saint-Philippe with 5086 inhabitants.

The analysis of the electricity consumption of the municipalities also shows disparities: Saint-Denis is the largest consumer with 529 MWh per year while Saint-Philippe is the least with $9 \mathrm{MW}$ h per year. Already, there seems to be a correlation between population size and electricity consumption (see Fig. 5).

\subsection{Bivariate analysis}

Our analysis is based on a description of the electricity consumption of municipalities according to population size. To simplify the consideration, we propose to use the natural logarithm. Using a scatter plot, we try to identify different behaviors to propose classes of municipalities. Three types of scatter plots could be highlighted (see Fig. 6).

The (a) scatter plot shows a positive correlation, which means a simultaneous increase in population size and electricity consumption. The (b) scatter plot shows a lack of correlation between our two variables, which could mean that other parameters, such as total industry or the number of firms may be more influential, and the (c) scatter plot indicates a negative correlation, which would mean that as the population size increases, consumption falls.

The expected result is (a) or (b). Indeed the purpose is to understand the importance of population size to the quantity of electricity consumed.

The (a) scatter plot is represented mathematically by the classic linear following formula:

$y=a x+b$

where $y$ is the energy consumption; $x$ is the population size; $a$ is the slope of the curve, which represents the quantity of electricity 


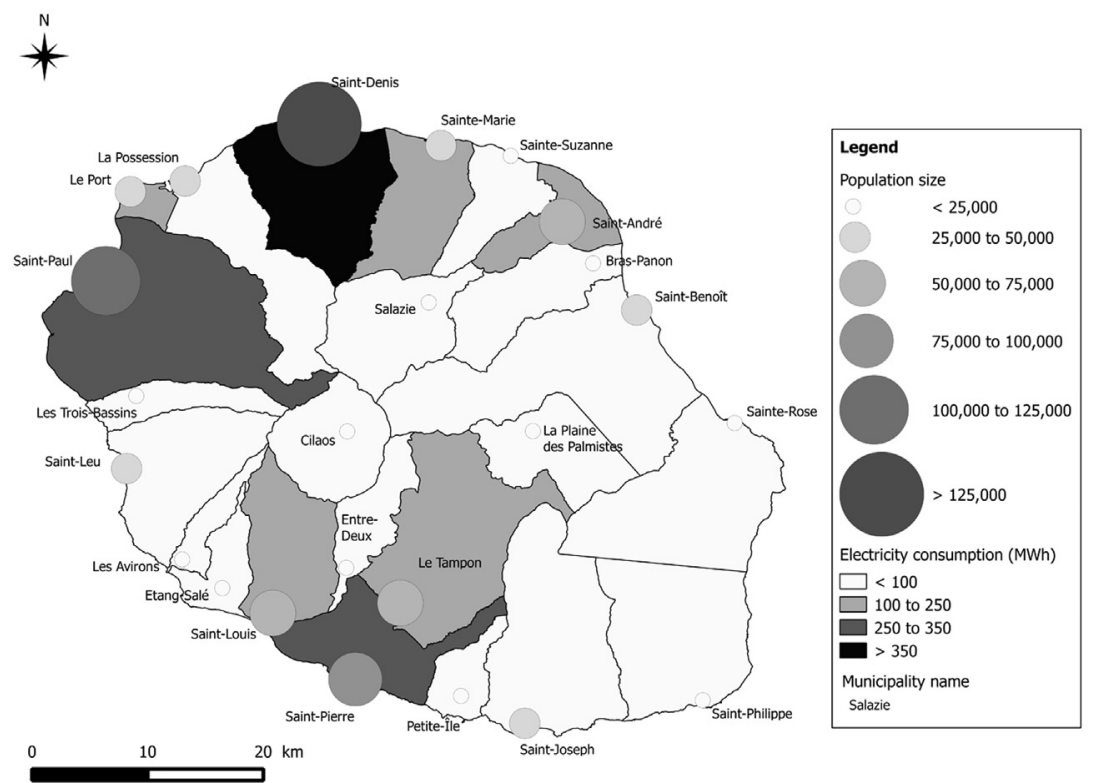

Fig. 5. Energy consumption and population size. Data source: IGN BD TOPO ${ }^{\mathbb{R}}$. ARER.
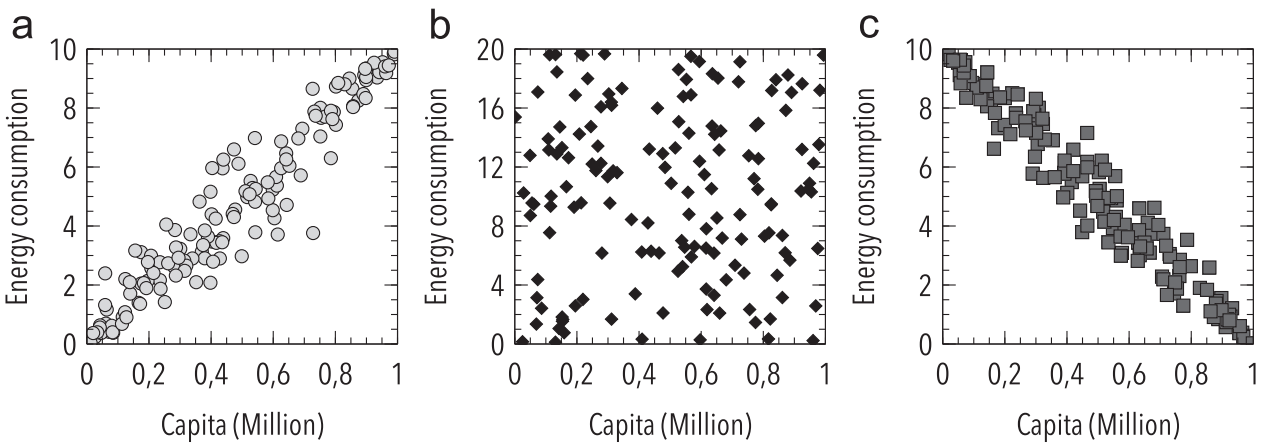

Fig. 6. The relationship between population and energy consumption.

consumed for an additional person; and $b$ can be considered as the incompressible average consumption by municipality, which is independent of population. Our purpose is to check how our data deviates from this linear model.

\subsection{Principal component analysis}

A principal component analysis is a multivariate data transformation method that is widely used as a technique to reduce the number of dimensions. Significant improvements can be achieved by mapping the data in a lower dimensional space. This method is used as a classifier for the study of the municipalities on Reunion. The aim is to highlight the similarities and identify the different groups and their characteristics.

Each municipality is considered as a point of a highdimensional space of $N$ dimensions, which is described as follows:

- High dimensional space

$$
x=a_{1} v_{1}+a_{2} v_{2}+\ldots+a_{N} v_{N}
$$

where $v_{1}, v_{2}, \ldots, v_{N}$ is the basis of the $N$ dimensional space.

- Lower dimensional space

$\hat{x}=b_{1} u_{1}+b_{2} u_{2}+\ldots+b_{N} u_{N}$

with $K \leq N$.
To limit the information loss due to the reduction, it is necessary to minimize $\|X-\hat{X}\|$. The best low-dimensional space is determined by the principal components of the covariance matrix. To define $\mathrm{K}$, a criterion is defined as follows:

$\frac{\sum_{i=1}^{K} \lambda_{i}}{\sum_{i=1}^{N} \lambda_{i}}>\xi$

where $\xi$ is a defined threshold (e.g., 0.85) and $\lambda_{i}$ are the eigenvalues.

Thus, the PCA could be helpful in identifying the variables that have a significant influence on the variance of the most influential principal component.

\section{Discussion and results}

\subsection{Electricity consumption-population analysis}

The scatter plot representing the electricity consumption depending on the population size of municipalities provides two assertions (see Fig. 7).

First, the shape approximates the linear form, which reflects the strong positive influence of the population size on electricity consumption. The expression of linear regression (dotted line on 
figure) is:

$$
\left\{\begin{array}{c}
\ln (\text { Consumption })=a \times \ln (\text { Capita })+b \\
a=-7.9865 \pm 0.3700 \\
b=1.1964 \pm 0.0395
\end{array}\right.
$$

Indeed, the mathematical translation provides a coefficient of determination $R^{2}$ of 0.954 , which allows the consideration of the population as a significant parameter to estimate the amount of electricity consumption. The energy balance report of Reunion highlights that $44.1 \%$ of the overall electricity consumption is due to households in 2010. The second largest consumption item contains the heavy consumer with $29 \%$, including industries, hospitals, airports, etc. [17].

The first regressive approach proposes a first prediction of energy consumption that is not really accurate (see Table 1). Four measurements of prediction performance are used to evaluate the prediction accuracy:

- The root mean squared error

$$
\operatorname{RMSE}=\sqrt{\frac{1}{n} \sum_{i=1}^{n}\left(y_{p i}-y_{i}\right)^{2}}
$$

- The mean absolute percentage

$$
\mathrm{MAPE}=\frac{1}{n} \sum_{i=1}^{n}\left|\frac{y_{p i}-y_{i}}{y_{i}}\right|
$$

- The summed squared of residuals

$$
\mathrm{SSE}=\sum_{i=1}^{n}\left(y_{p i}-y_{i}\right)^{2}
$$

where $n$ represents the number of observations and $y_{p i}$ is the predicted value.

The total energy consumption is particularly underestimated. Indeed, the difference between the data and predicted values is approximately $75.70 \mathrm{GW}$ h. To put this result in perspective, the gap observed is nearly the value of the energy consumption of the municipality of Sainte Marie. The underestimation is $3.16 \%$ of the total energy consumption.

Second, Fig. 7 shows three groups of municipalities adopting different behavior. Indeed, we can identify a first group, the "medium" group, consisting of 14 municipalities, which strictly follow the theoretical curve. These municipalities are those for which the population variable is greater for electricity consumption. This group is very diverse and includes cities such as SaintDenis and Saint-Philippe, which are very different. We actually find two types of cities in this group: cities with low consumption (less than $100 \mathrm{MW}$ h per year) and low population (less than 50,000 inhabitants)(the medium a group), and cities with high consumption (more than $100 \mathrm{MW} \mathrm{h}$ ) and large size (more than 50,000 inhabitants)(the medium b group). In the first subgroup, there are Cilaos, Entre-Deux, Sainte-Suzanne, Saint-Philippe, La Plaine des Palmistes, Trois Bassins, Bras Panon, La Possession, and Saint-Benoît. In the second subgroup, we find Saint-Denis, SaintPierre, Saint-Louis, Saint-Paul and Saint-André.

Then, we can identify a "low" group, consisting of seven cities in which the theoretical curve overestimates the electricity consumption. This overestimation may have two explanations: either their population is extremely energy efficient, but there is no official information or data which allow to establish it, or they are municipalities where there is little or no industrial activity (the second largest item of electricity energy consumption). These municipalities are Les Avirons, Petite Ile, Sainte-Rose, Saint-Leu, Salazie, Saint-Joseph, and Le Tampon. There are small towns that show a gross population density below 500 inhabitants per square kilometer (see Fig. 8). Aside from Saint-Leu and Les Avirons, they are located in the south and the east of the Island and are well known for their rural appearance. They claim it also through various events such as Miel Vert, Florilèges or Fête Safran, which are feasts taking place over a week and celebrating the local rural production of honey, flowers and turmeric, respectively. There is also the Rural University of the Indian Ocean that began in 2004, which consists of a series of conferences and roundtables on rural planning and its evolution. Regarding Les Avirons, it is a city often considered a bedroom town which has no activity zones [1].

Finally, we can identify a "high" group, with three cities in which the theoretical curve underestimates consumption. This means that for these municipalities, the population variable is not sufficient to explain the electricity consumption. We have on one side the cities of Le Port and Sainte-Marie, which stand out for their industrial activities. In fact, Le Port contains the only harbor

Table 1

Energy consumption prediction errors.

\begin{tabular}{lllll}
\hline & \multicolumn{2}{l}{ Regression error } & \\
\cline { 2 - 5 } & SSE & $\begin{array}{l}\text { Adjusted } R- \\
\text { square }\end{array}$ & RMSE & MAPE \\
\hline Municipalities energy consumption & 1.592 & 0.954 & 0.269 & 17.669 \\
\hline
\end{tabular}

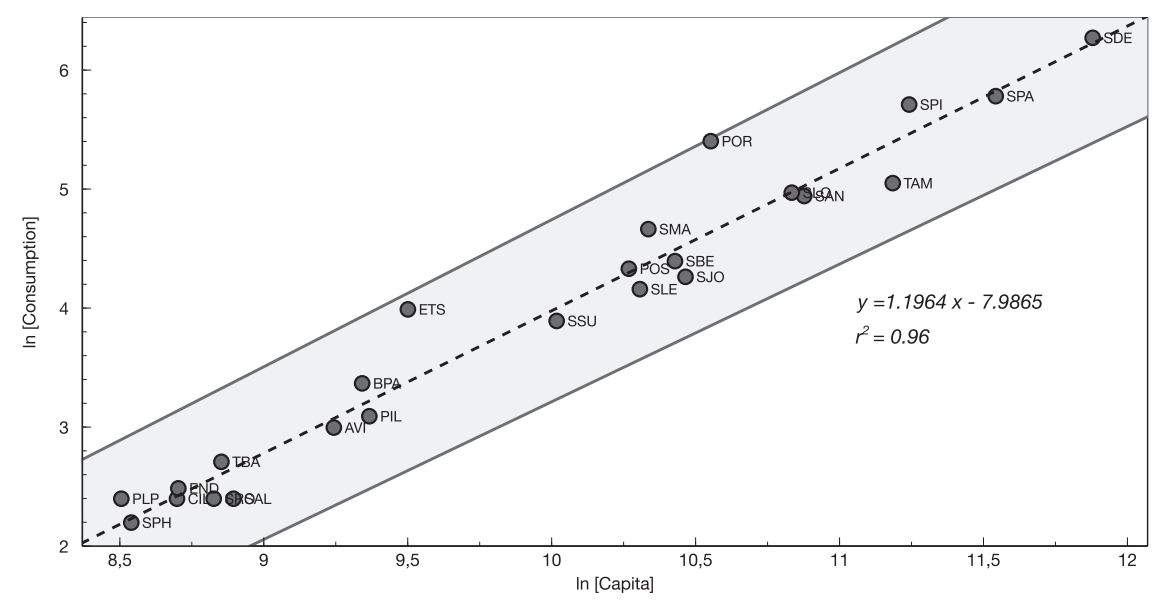

Fig. 7. Energy consumption distribution. Nb: Appendix 1 provides a summary mapping between acronyms used in graphics and names of municipalities. 
on the island and is thus a strategic location for many companies dependent on the harbor facilities. Despite its small area, the municipality contains 928 industrial sites, which account for $12.53 \%$ of the total industrial buildings on Reunion (BD TOPO, IGN). Sainte-Marie has within it the main airport of the island. This activity is a large consumer of electricity in particular for cooling, ventilation and lighting of buildings, runway lighting, etc. The case of Etang-Salé is different from both previous cases because it does not contain harbor or airport activities. Nevertheless, industrial activity is present in the municipality and it grants the third largest area of the town to industrial activity (behind Le Port and Saint-Pierre) [1]. This is all the more striking because Etang-Salé is a mid-sized city in terms of population, which reflects the importance of industry in the municipality (see Fig. 8). The analysis of the number of square meters of area per capita also shows that these are the three cities that display greater area per capita (AGORAH data) (see Fig. 9).

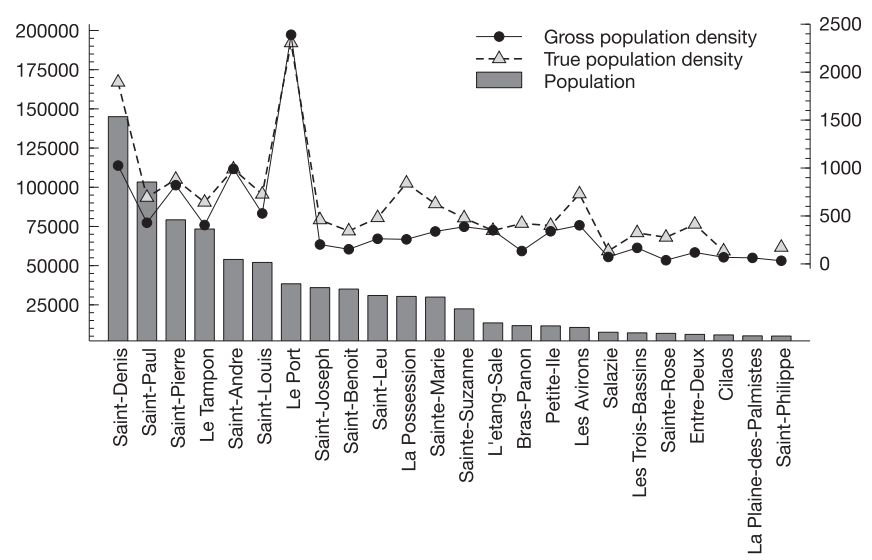

Fig. 8. Population size distribution.

\subsection{Principal component analysis}

The previous bivariate analysis reveals four classes of cities. The errors of estimation noticed on the high and low groups allow us to conclude that the population (POP) is not able to completely explain the electricity consumption (Econ). Considering the concerned cities and the global statistics of Reunion consumption, we suggest completing our analysis. First, to fully understand the diversity of the areas of the cities, we propose to supplement the variable population and use the variable population density. Then, we propose to complete the dataset with data on the industrial activity of the city and on the standard of living of households. Performing a Principal Components Analysis (PCA) with these new variables would explore the classes made previously. We therefore considered in our analysis the following variables that refer to the population and industrial activity of the territory, which seems most suitable in light of economic characteristics and customer segmentation presented in Section 2:

- The electricity consumption (MW h).

- The population density (capita/ $\mathrm{km}^{2}$ ).

- The activity area per capita $\left(\mathrm{m}^{2} /\right.$ capita).

- The number of industrial buildings.

- The reported net income.

In this study, the dataset is made of 24 rows of individuals (Municipalities) and the 5 previous variables. Appendix 1 summarizes the data used for the PCA. This multivariate exploratory approach will answer several questions:

- Are there similarities between the municipalities according to the variables? What are the characteristics of these groups?

- Can we observe a significant variability between the individual cities?

- Is there any linear relationship between variables?

- Can the municipalities be summarized by a smaller number of variables?

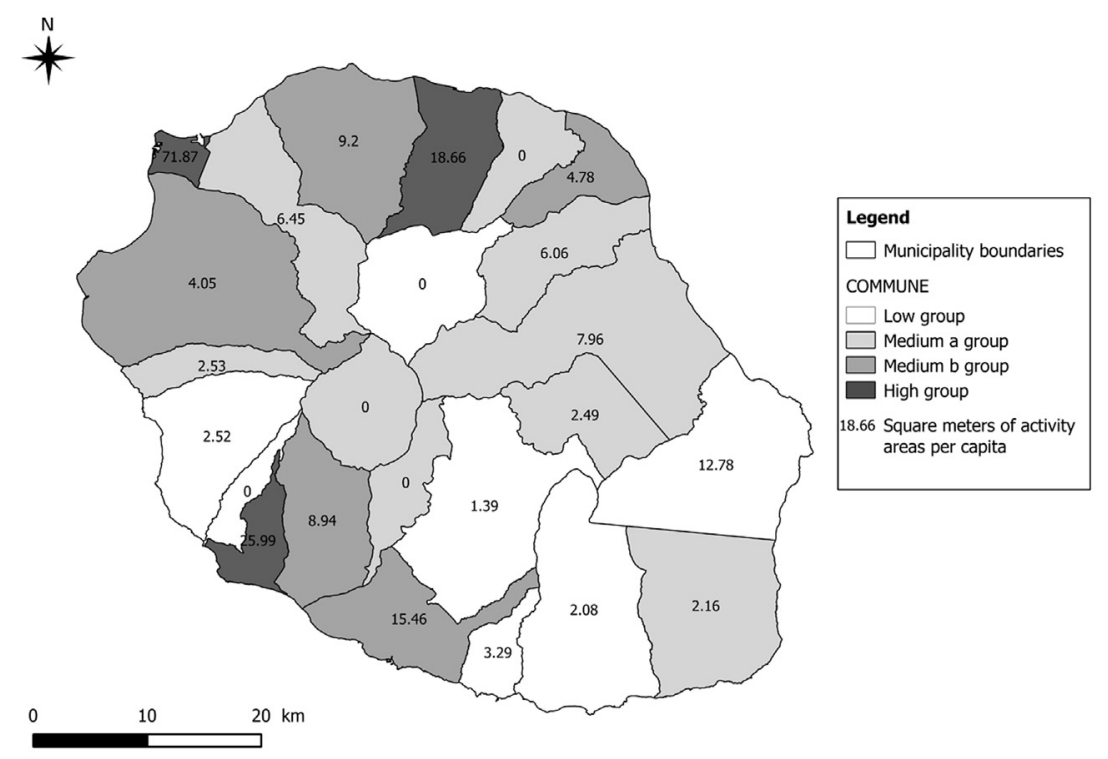

Fig. 9. Classification of cities. Data source: IGN BD CARTO ${ }^{\circledR}$. 
The bar plot of the component inertia percentage allows an evaluation of the projection quality of the dataset. As shown in Fig. 10, Dimension 1 and 2 explain 93.7\% of the variances. Thus, these dimensions are representative of all the variables.

The quality of variables or individuals projected on the map is described by a parameter called $\cos ^{2}$. Fig. 11 visualizes the most correlated variables on the correlation circle. The variables have a $\cos ^{2}>0.6$ for the dimension 1 . The activity has a better projection on dimension 2 compared to the first, 0.595 and 0.347 , respectively. Thus, the variables projection in the [Dim.1, Dim. 2] plane have a $\cos ^{2}>0.847$.

The contribution is another indicator of the quality of the PCA; it represents the part of an individual or a variable in the construction of one of the dimension axes. From the perspective of the variables, the observation of contributions highlights that the activity has a contribution of $45 \%$ on $\operatorname{Dim} 2$ (10\% on Dim 1.). Concerning the analysis of individuals, there are two special cases.
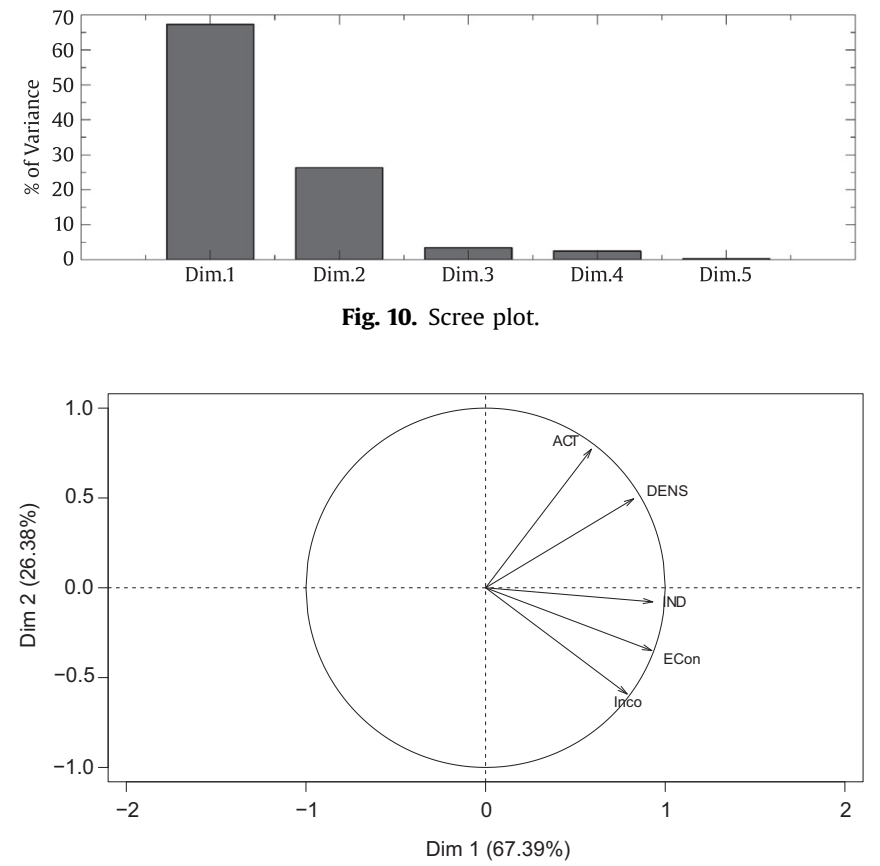

Fig. 11. Variables graph.
The municipalities of St Denis and Le Port contribute greatly to the construction of axis 1 , at $29 \%$ and $26 \%$, respectively.

On the individual factor map, see Fig. 12, we represent the municipalities (black color) which have a $\cos ^{2}>0.8$. A group of 9 municipalities can be observed on the left, which corresponds to municipalities with low energy consumption, low densities, a limited number of industrial buildings and low income. Regarding Dim 2, this group has a medium value in terms of activity area/ capita (ACT). In the upper right part of the map, we can find Le Port, which is a municipality with high value for all variables. Indeed Le Port hosts the unique industrial port of the island, which explains the high value of activity area/capita. In the bottom-right, there is St Denis, which is the capital city of Reunion. It has a high density of population, which is why its ACT value is low.

On individual factor map 2 (see Fig. 13), we showed the classes obtained by the previous method (regression). The grouping of cities of classes "low" and "medium low" is noticeable on the graph. These cities combine the following features: low energy consumption, low density, low income, few industrial buildings, and low surface activity area per capita.

The high group is concentrated in the upper-right side of the graph. This confirms the analysis conducted previously, which indicated that industrial activity explains the underestimation of the energy consumption of the municipalities of Le Port, SainteMarie and Etang-Salé.

Finally, in the bottom-right of the graph, we can find the municipalities of the medium group. These cities therefore have a high-energy consumption, high population density, large number of industrial buildings and high income, but the activity surface area per capita is low. The municipality that takes the least strong value on the axis Dim 2 is Saint-Denis, which nevertheless has 133 hectares of activity surface. This makes it the second largest city behind Le Port with 276 hectares [1]. The reason is likely due to the size of the population of Saint-Denis: it is so large that it makes the weight of activities less decisive.

\subsection{Synthesis}

To understand the relationship between population and electricity consumption in cities, we made use of two methods. The results obtained highlight the existence of three city profiles:

- a high group, with cities whose industrial activity is of great importance;

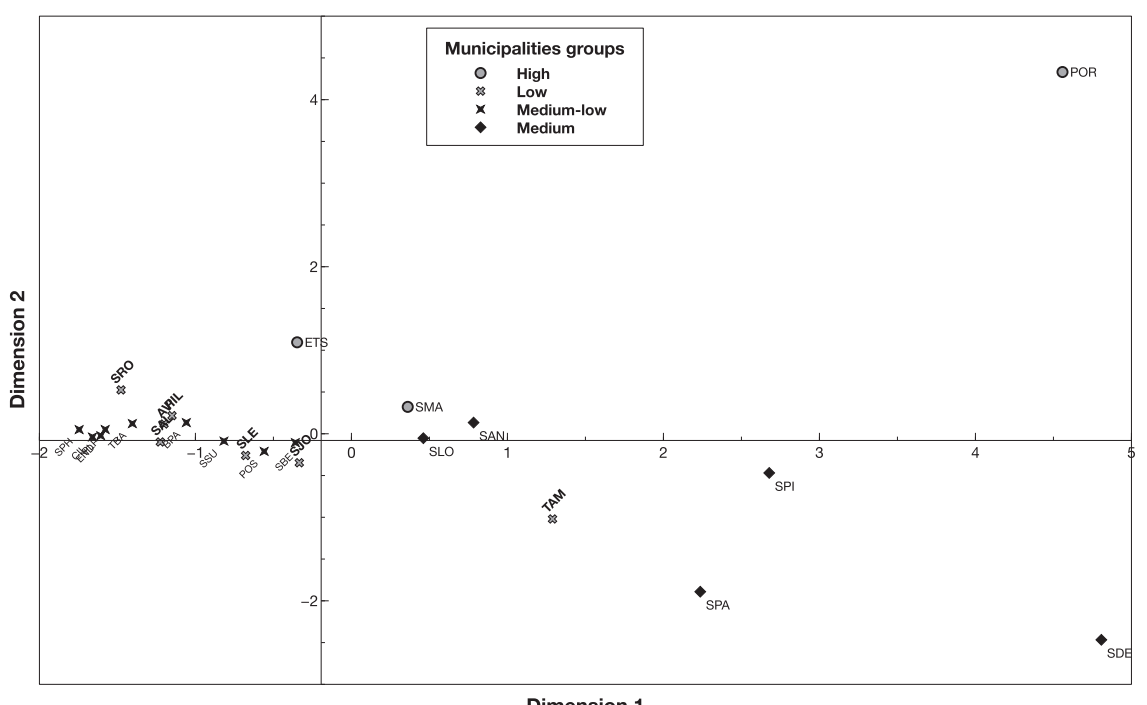

Fig. 12. Individual factor map 1: representative individuals. 


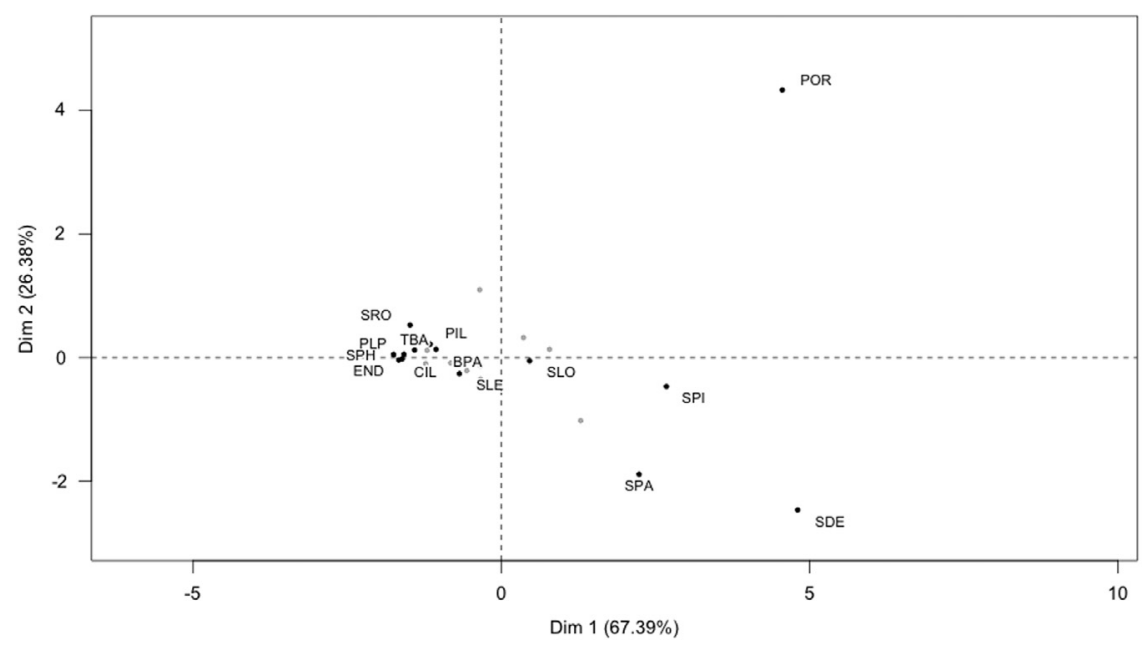

Fig. 13. Individual factor map 2: representation of the linear regression classes.

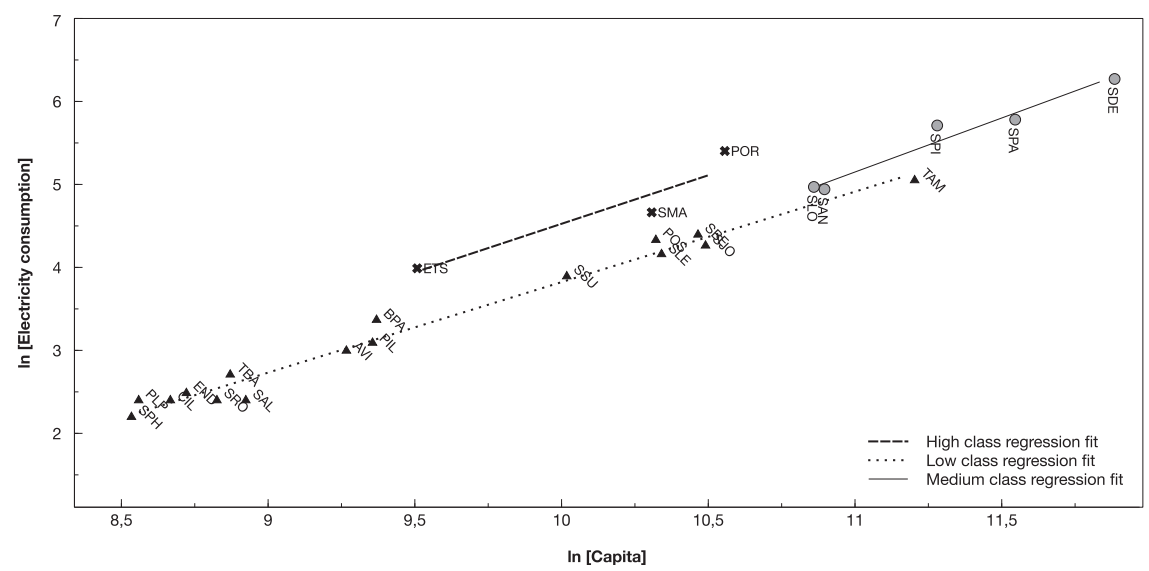

Fig. 14. Results of the multi-regression.

- a medium group, whose cities are large and heavy consumers but with no major industrial activity (the medium group of the bivariate analysis);

- a low group, which regroups medium low and low groups: it contains small cities with low electricity consumption and few industrial activities.

Consideration of these three groups leads us to make three linear regressions that improve the quality of our estimations (see Fig. 14).

We can see in Table 2 that, although the calculation of adjusted $R^{2}$ is not better than for the single regression (especially for high group with 0.801), the error coefficient MAPE decreases (from 17.669 to 8.047). This result shows the effects of compensation between municipalities in the mono regression and supports the conclusion about the necessity of classifying cities to identify patterns in their energy consumption.

After considering the classification of the municipalities, the multi-regression approach highlights a more accurate energy prediction. In the first case of one regression, the estimated value of total consumption is $2395 \mathrm{GW} \mathrm{h}$ instead of $2469 \mathrm{GW} \mathrm{h}$. The difference is nearly equivalent to the consumption of Sainte Marie (SMA), which is the fourth municipality in terms of economic activity and industry. The result obtained from the multiregression is $2464 \mathrm{GW} \mathrm{h}$, which leads to a smaller difference.

The methodology defined in the present paper is based on both a PCA and a multi-regression analysis and significantly improved the results. If only the total electricity consumption prediction is considered, this enhancement is not clearly conclusive. However, the MAPE error brings additional understanding, decreasing from a value of 17.669 to 2.8594 , by mono and multi regressions, respectively.

This result clearly reflects that in the first mono regression, several overestimations are partly offset by the underestimations of electricity consumption in other municipalities. Thus, observing only the total electricity consumption does not supply sufficient information in the results.

Based on the classification investigated in 2010, a prediction of electricity consumption is proposed for the next two years. Fig. 15 shows the results of the prediction from 2010 to 2012 on the municipalities and the estimation of the global consumption of Reunion Island. The prediction results for the three years are all within a reasonable range (MAPE $<3.5$ and RMSE $<0.14$ ).

As a general observation, our method is based on a three step PCA - Classification, and regression shows that is possible to predict electricity consumption with high accuracy. This approach is particularly interesting when socio-economic data are considered, as they are generally at an annual step.

\section{Conclusion}

Energy issues on islands are a result of the difficulty of supply. Using renewable energy to achieve energy independence is a common consensus. However, the method to achieve this independence remains uncertain. The proposed standard methods go 
Table 2

Energy consumption prediction errors: the three groups.

\begin{tabular}{|c|c|c|c|c|c|c|c|c|}
\hline \multirow[t]{2}{*}{ Class } & \multirow[t]{2}{*}{ Municipalities labels } & \multicolumn{2}{|c|}{ INSEE data } & \multirow{2}{*}{$\begin{array}{l}\text { Regression fit } \\
\text { Energy }\end{array}$} & \multicolumn{4}{|c|}{ Regression error } \\
\hline & & Energy & Population & & SSE & $R$-square & RMSE & MAPE \\
\hline High & ETS & 3989 & 9508 & 3928 & 0.099 & 0.901 & 0.315 & 3.425 \\
\hline High & POR & 5403 & 10,556 & 5212 & & & & \\
\hline High & SMA & 4663 & 10,307 & 4907 & & & & \\
\hline Medium & SAN & 4942 & 10,896 & 5027 & 0.051 & 0.961 & 0.130 & 1.422 \\
\hline Medium & SDE & 6271 & 11,885 & 6298 & & & & \\
\hline Medium & SLO & 4970 & 10,860 & 4981 & & & & \\
\hline Medium & SPA & 5781 & 11,546 & 5862 & & & & \\
\hline Medium & SPI & 5710 & 11,280 & 5521 & & & & \\
\hline Low & AVI & 2996 & 9267 & 3035 & 0.226 & 0.983 & 0.127 & 3.200 \\
\hline Low & PIL & 3091 & 9356 & 3131 & & & & \\
\hline Low & SAL & 2398 & 8924 & 2664 & & & & \\
\hline Low & SJO & 4263 & 10,491 & 4360 & & & & \\
\hline Low & SLE & 4159 & 10,341 & 4198 & & & & \\
\hline Low & SRO & 2398 & 8826 & 2557 & & & & \\
\hline Low & TAM & 5050 & 11,203 & 5132 & & & & \\
\hline Low & BPA & 3367 & 9369 & 3146 & & & & \\
\hline Low & CIL & 2398 & 8667 & 2385 & & & & \\
\hline Low & END & 2485 & 8721 & 2444 & & & & \\
\hline Low & PLP & 2398 & 8559 & 2268 & & & & \\
\hline Low & POS & 4331 & 10,321 & 4177 & & & & \\
\hline Low & SBE & 4394 & 10,465 & 4332 & & & & \\
\hline Low & $\mathrm{SPH}$ & 2197 & 8534 & 2242 & & & & \\
\hline Low & SSU & 3892 & 10,018 & 3848 & & & & \\
\hline \multirow[t]{2}{*}{ Low } & TBA & 2708 & 8871 & 2606 & & & & \\
\hline & TOTAL & 94,253 & 238,770 & 94,264 & 0.3729 & 0.9792 & 0.130 & 2.8594 \\
\hline
\end{tabular}
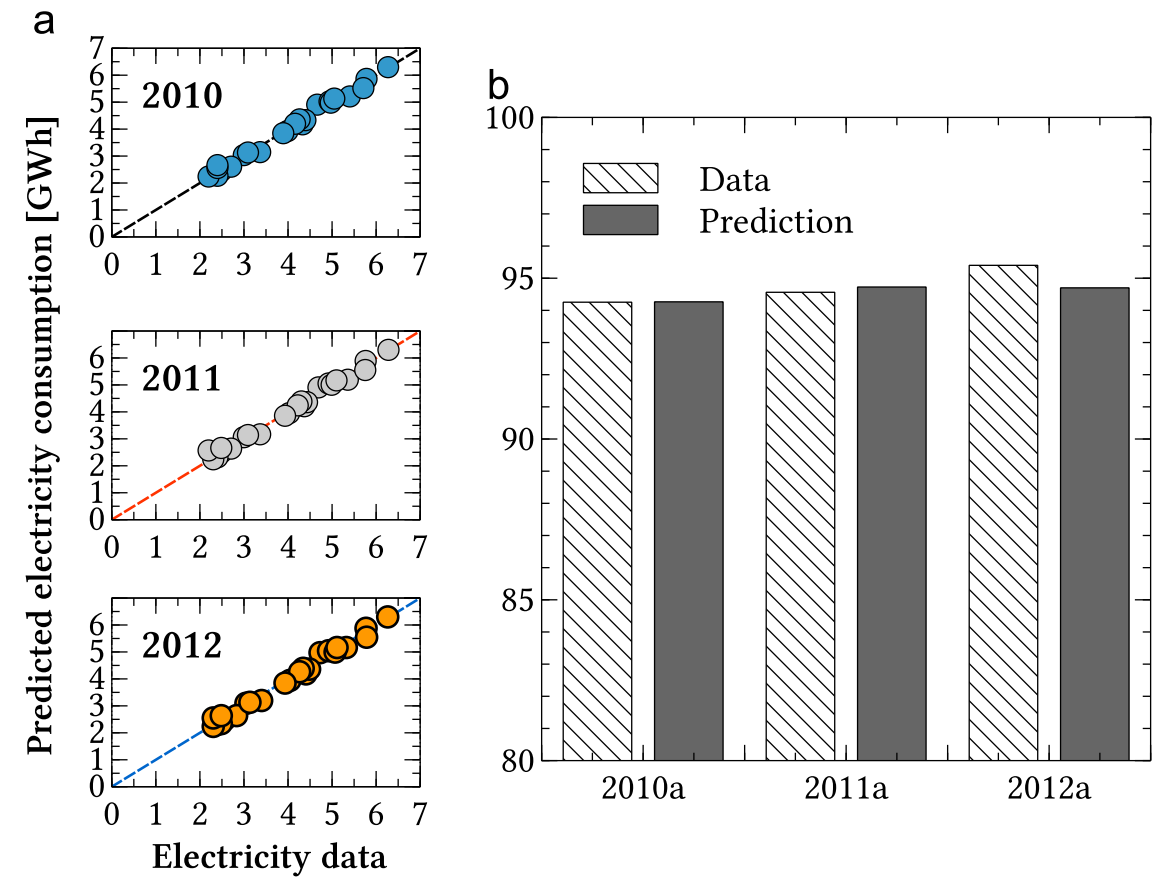

Fig. 15. Electricity prediction from 2010 to 2012: (a) Municipalities prediction, (b) Reunion Island prediction.

through the accentuation of technical research to improve the quality of supply (the fight against the intermittency factor), storage systems or influencing the behavior of the user. In this paper, we propose instead to change the scale of the analysis: to reflect a finer scale by considering the integration of micro-systems more suited to localized demand. This method requires an understanding of electricity demand: on the city scale, what are the factors that explain power consumption?
Population growth goes along with the growth in energy demand. To meet the need effectively, it is important to understand the energy demand, which allows efficient energy production. A big step takes place in the localization of the demand. Thus, to envisage the consumption of a territory, it is important to know how to characterize and differentiate the entities of a territory. One preliminary thought focuses on the population and its impact on the energy consumption of an entity. This work has demonstrated that in the case of Reunion Island, the population factor is an important 
but incomplete electricity consumption factor for cities. This result is a good beginning for planning the energy consumption of a territory, in particular, by dividing the territory into various subsets. The split would allow the understanding of the eventuality of the microstructures of production and a closeness distribution. This would feed the debate on sustainable cities and districts, especially on "energy independence". Knowledge of the consumption structure is expected to help plan the production system (sizing of a proximity system possibly) and distribution in a better way.

The present study highlights that an average overall approach does not faithfully capture the disparities that may exist on a small island space. Therefore, for a more realistic forecast, it is necessary to grasp the territory as a set of different groups of cities that behave differently. The study of the behavior of municipalities enables us to distinguish three or four different classes. The specific characteristics of each category make it possible to characterize their energy consumption. The use of the classes allowed a reduction in the error of estimation of the consumption of cities (see MAPE error). This characterization is an asset for energy planning.

Indeed, this estimation method using the classification is a preliminary step to the study of the energy consumption of a territory, enabling the establishment of a forecasting process in the future. This work was conducted using a static approach. To refine the analysis, further research should achieve a dynamic temporal approach to obtain the evolution of each of the entities. Likewise, the use of a finer scale, such as the district, could provide more knowledge about the structure of energy demand.

\section{Appendix 1}

\begin{tabular}{|c|c|c|c|c|c|c|c|}
\hline ID & Name & $\begin{array}{l}\text { Electricity } \\
\text { cosumption } \\
(\mathrm{MW} \mathrm{h})\end{array}$ & $\begin{array}{l}\text { Population den- } \\
\text { sity (capita/km²) }\end{array}$ & $\begin{array}{l}\text { Activity area per } \\
\text { capita ( } \mathrm{m}^{2} / \text { capita) }\end{array}$ & $\begin{array}{l}\text { Number of } \\
\text { industrial } \\
\text { buildings }\end{array}$ & $\begin{array}{l}\text { Reported net } \\
\text { income }(€)\end{array}$ & $\begin{array}{l}\text { Additional qualita- } \\
\text { tive variable:Group }\end{array}$ \\
\hline BPA & Bras-Panon & 29 & 134,31 & 6,06 & 232 & $92,563,604$ & Medium a \\
\hline CIL & Cilaos & 11 & 68,81 & - & 78 & $32,549,474$ & Medium a \\
\hline END & Entre-Deux & 12 & 119,32 & - & 66 & $53,351,616$ & Medium a \\
\hline PLP & $\begin{array}{l}\text { Plaine des } \\
\text { Palmistes }\end{array}$ & 11 & 62,75 & 2,49 & 89 & $44,486,585$ & Medium a \\
\hline POS & $\begin{array}{l}\text { La } \\
\text { Possession }\end{array}$ & 76 & 256,05 & 6,45 & 164 & $363,265,672$ & Medium a \\
\hline POR & Le Port & 222 & 2390,37 & 71,87 & 928 & $206,575,545$ & High \\
\hline TAM & Le Tampon & 156 & 405,01 & 1,39 & 856 & $618,914,803$ & Low \\
\hline AVI & Les Avirons & 20 & 402,6 & - & 93 & $113,387,004$ & Low \\
\hline TBA & $\begin{array}{l}\text { Les Trois- } \\
\text { Bassins }\end{array}$ & 15 & 167,32 & 2,53 & 122 & $48,142,354$ & Medium a \\
\hline ETS & $\begin{array}{l}\text { L'Etang- } \\
\text { Salé }\end{array}$ & 54 & 350,27 & 25,99 & 174 & $160,450,568$ & High \\
\hline PIL & Petite-Île & 22 & 340,1 & 3,29 & 116 & $102,705,061$ & Low \\
\hline SAN & $\begin{array}{l}\text { Saint- } \\
\text { André }\end{array}$ & 140 & 991,16 & 4,78 & 420 & $367,414,426$ & Medium b \\
\hline SBE & $\begin{array}{l}\text { Saint- } \\
\text { Benoît }\end{array}$ & 81 & 152,47 & 7,96 & 395 & $241,988,775$ & Medium a \\
\hline SDE & Saint-Denis & 529 & 1025,47 & 9,2 & 908 & $1,661,092,857$ & Medium b \\
\hline SMA & $\begin{array}{l}\text { Sainte- } \\
\text { Marie }\end{array}$ & 106 & 338,32 & 18,66 & 445 & $333,790,029$ & High \\
\hline SRO & Sainte-Rose & 11 & 38,32 & 12,78 & 36 & $36,134,038$ & Low \\
\hline SSU & $\begin{array}{l}\text { Sainte- } \\
\text { Suzanne }\end{array}$ & 49 & 387,48 & - & 209 & $181,760,458$ & Medium a \\
\hline SJO & $\begin{array}{l}\text { Saint- } \\
\text { Joseph }\end{array}$ & 71 & 202,24 & 2,08 & 468 & $239,298,058$ & Low \\
\hline SLE & Saint-Leu & 64 & 261,99 & 2,52 & 222 & $283,051,176$ & Low \\
\hline SLO & Saint-Louis & 144 & 526,51 & 8,94 & 437 & $336,030,815$ & Medium b \\
\hline SPA & Saint-Paul & 324 & 429,35 & 4,05 & 653 & $1,095,831,063$ & Medium b \\
\hline SPH & $\begin{array}{l}\text { Saint- } \\
\text { Philippe }\end{array}$ & 9 & 32,86 & 2,16 & 27 & $29,836,333$ & Medium a \\
\hline SPI & $\begin{array}{l}\text { Saint- } \\
\text { Pierre }\end{array}$ & 302 & 821,27 & 15,46 & 875 & $690,526,987$ & Medium b \\
\hline SAL & Salazie & 11 & 72,28 & - & 323 & $35,801,191$ & Low \\
\hline
\end{tabular}

\section{References}

[1] AGORAH. Observatoire des Zones d'Activité à La Réunion Atlas cartographique 2011. AGORAH; 2012.

[2] Bouckaert S, Mazauric V, Maïzi N. Expanding renewable energy by implementing demand response. Energy Procedia 2014;61:1844-7.
[3] Chen F, Duic N, Manuel Alves L, da Graça Carvalho M. Renewislands-renewable energy solutions for islands. Renew Sustain Energy Rev 2007;11:1888-902.

[4] Dalama M-G. Lî̃le de la Réunion et le tourisme: d'une île de la désunion à la Réunion des Hauts et Bas. L'Espace géographique 2005;34:342-9. 
[5] EDF SEI, île de La Réunion. Bilan prévisionnel pluriannuel des investissements en production. 2009

[6] EDF SEI, Île de La Réunion. EDF à La Réunion. Nos engagements. Les priorités d'EDF. 〈〈http://reunion.edf.com/edf-a-la-reunion/nos-engagements/les-prior ites-d-edf-a-la-reunion-49330.html $\rangle, 07 / 04 / 2015.2013$.

[7] Elahee K. Energy management in a small-island developing economy: the case of mauritius. Chapter 12. In: Clark WW, editor. Global sustainable communities handbook. Boston: Butterworth-Heinemann; 2014. p. 293-303.

[8] Fillon, F. Decree n. 2011-240, March 4, amending Decree No. 2001-410 concerning the conditions of purchase electricity from producers benefiting from the purchase obligation Official Journal. 2011.

[9] Graham E. Singapore in the 1990s: can population policies reverse the demographic transition? Appl Geogr 1995:15:219-32.

[10] INSEE. Tableau économique de la Réunion. 2014.

[11] Jauze JM. Les centralités emboîtées de l'espace réunionnais Mappemonde. 1998. p. 27-30.

[12] Kaldellis JK, Gkikaki A, Kaldelli E, Kapsali M. Investigating the energy autonomy of very small non-interconnected islands: A case study: Agathonisi, Greece. Energy Sustain Dev 2012;16:476-85.

[13] Kotzebue JR, Bressers HTA, Yousif C. Spatial misfits in a multi-level renewable energy policy implementation process on the Small Island State of Malta. Energy Policy 2010;38:5967-76.

[14] MEEDDAT Programmation pluriannuelle des investissements de production d'électricité Période 2009-2020. 2009. p. 132

[15] MEEDM, MEIE. Grenelle Environnement - Photovoltaïque. La France en avance sur ses objectifs. Ajustement des tarifs pour les projets professionnels et les gros projets. Concertation à l'automne sur une adaptation du dispositif. 2010.
[16] Niles K, Lloyd B. Small Island Developing States (SIDS) \& energy aid: impacts on the energy sector in the Caribbean and Pacific. Energy Sustain Dev 2013; 17:521-30.

[17] Observatoire Energie Réunion, 2013. Bilan Energétique Île de La Réunion 2012. ARER

[18] Praene JP, David M, Sinama F, Morau D, Marc O. Renewable energy: progressing towards a net zero energy island, the case of Reunion Island. Renew Sustain Energy Rev 2012;16:426-42.

[19] Riva Sanseverino E, Riva Sanseverino R, Favuzza S, Vaccaro V. Near zero energy islands in the Mediterranean: Supporting policies and local obstacles. Energy Policy 2014;66:592-602.

[20] Sinama F. Étude de la production d'électricité à partir de l'énergie thermique des mers à l'île de la Réunion : modélisation et optimisation du procédé Laboratoire PIMENT Université de la Réunion, Reunion; 2011. p. 168.

[21] Vaxelaire, D. L'histoire de La Réunion. De 1848 à 2012. ORPHIE; 2012.

22] Weisser D. On the economics of electricity consumption in small island developing states: a role for renewable energy technologies? Energy Policy 2004;32:127-40.

[23] Weisser D. Power sector reform in small island developing states: what role for renewable energy technologies? Renew and Sustain Energy Rev 2004;8:101-27.

[24] Yip PSF, Lee J, Chan B, Au J. A study of demographic changes under sustained below-replacement fertility in Hong Kong SAR. Soc Sci Med 2001:53:1003-9.

[25] Yu X, Taplin R, Akura T. A framework for energy policy-making in the Pacific Islands. Energy Policy 1997;25:971-82. 